\title{
Quality Improvement of Pancreatic Surgery by Centralization in the Western Part of the Netherlands
}

\author{
Gea A. Gooiker, MD ${ }^{1}$, Lydia G. M. van der Geest, MSc $^{2}$, Michel W. J. M. Wouters, MD ${ }^{1}$, Marieke Vonk, MD ${ }^{1}$, \\ Tom M. Karsten, MD, $\mathbf{P h D}^{3}$, Rob A. E. M. Tollenaar, MD, $\mathbf{P h D}^{1}$, and Bert A. Bonsing, MD, $\mathbf{P h D}^{1}$ \\ ${ }^{1}$ Department of Surgery, Leiden University Medical Centre, Leiden, The Netherlands; ${ }^{2}$ Comprehensive Cancer Centre \\ West, Leiden, The Netherlands; ${ }^{3}$ Department of Surgery, Reinier de Graaf Hospital, Delft, The Netherlands
}

\begin{abstract}
Background. Centralization of pancreatic surgery in highvolume hospitals is under debate in many countries. In the western part of the Netherlands, the professional network of surgical oncologists agreed to centralize all pancreatic surgery from 2006 in two high-volume hospitals. Our aim is to evaluate whether centralization of pancreatic surgery has improved clinical outcomes and has changed referral patterns.
\end{abstract}

Materials and Methods. Data of the Comprehensive Cancer Centre West (CCCW) of all 249 patients who had a resection for suspected pancreatic cancer between 1996 and 2008 in the western part of the Netherlands were analyzed. Multivariable modeling was used to evaluate survival for 3 time periods; 1996-2000, 2001-2005 (introduction of quality standards), and 2006-2008 (after centralization). In addition, the differences in referral pattern were analyzed.

Results. From 2006, all pancreatic surgery was centralized in 2 hospitals. The 2-year survival rate increased after centralization from $39 \%$ to $55 \%(P=.09)$ for all patients who had a pancreatic resection for pancreatic cancer. After adjustment for age, tumor location, stage, histology, and adjuvant treatment, the latter period was significantly associated with improved survival (hazard ratio [HR] 0.50; 95\% confidence interval [95\% CI] 0.34-0.73).

Conclusions. Centralization of pancreatic surgery was successful and has resulted in improved clinical outcomes

(C) The Author(s) 2011. This article is published with open access at Springerlink.com

First Received: 23 August 2010; Published Online: 5 May 2011

R. A. E. M. Tollenaar, MD, PhD

e-mail: r.a.e.m.tollenaar@lumc.nl in the western part of the Netherlands, demonstrating the effectiveness of centralization.

In many countries, the question whether high-risk surgery should be centralized in high-volume centers is prominent in the quality of healthcare debate. The association between high procedural volume and improved outcomes is generally accepted, and the strongest association is seen with high-risk, low volume procedures, such as pancreatic or esophageal surgery. ${ }^{1-8}$ Authors suggest that especially these high-risk procedures can benefit from concentration in high-volume centers. ${ }^{9}$ However, translating these results into practice is challenging.

In the Netherlands, the annual incidence of pancreatic cancer is around 1700 new cases of pancreatic cancer and around 440 cases of extra hepatic bile duct cancer (source: Netherlands Cancer Registry). A resection is done in approximately $15 \%$ of the cases, resulting in 300 pancreatic resections for malignant disease each year. For more than a decade, there is an ongoing debate for minimal volume standards for pancreatic resections. However, despite the plea for centralization, little had changed in referral patterns or postoperative mortality in the period 1994-2004. ${ }^{10}$

The Dutch Healthcare Inspectorate considers a minimal volume standard for pancreatic resections, but already does demand a minimal volume for esophageal resections. Recently, Wouters et al. showed a reduction of postoperative morbidity and length of stay after centralization of esophageal resections in the Netherlands. ${ }^{11}$ The postoperative mortality fell from $12 \%$ to $4 \%$. However, although many studies on the volume outcome relationship for pancreatic surgery exist, reports showing actual improvement of quality of care after centralization have only been scarce.

In the western part of the Netherlands, 9 hospitals are affiliated with the Comprehensive Cancer Centre West 
(CCCW), 1 of the 8 comprehensive cancer centers in the country. In 2001 the professional network of surgical oncologists (PNSO) in the region formulated quality standards for hospitals performing pancreatic surgery (shown in the frame). Furthermore, they declared the intention to centralize pancreatic surgery after a period of monitoring. In 2005 the PNSO agreed to centralize all pancreatic surgery in 2 centers from January 1, 2006.

In this study the outcomes of the centralization process in the western part of the Netherlands are reported. Quality criteria for pancreatic surgery formulated by the PNSO of the CCCW in the Netherlands include: (1) new patients are preoperatively and postoperatively discussed in a multidisciplinary board with a gastroenterologist and a radiologist; (2) all patients are operated on by an experienced surgeon; (3) the hospital has an intensive care unit, intervention radiology, and gastroenterology department; and (4) all patients are operated on by two surgeons together.

\section{METHODS}

\section{Hospitals and Centralization}

From 1996 until 2005 the CCCW had 11 affiliated hospitals. After 2 mergers in 2006, 9 affiliated hospitals were left: 1 academic center, 6 teaching hospitals, and 2 nonteaching hospitals. All are located in the midwestern part of the Netherlands and fully cover the region west. This area is mainly urban with 1.7 million inhabitants. Traveling distances between hospitals are $45 \mathrm{~km}$ (30 miles) maximum.

From 1996 until 2005 all hospitals performed pancreatic surgery. Since 2006 pancreatic surgery was centralized in 2 hospitals: the Leiden University Medical Centre (LUMC), an academic center, and the Reinier de Graaf Hospital (RdGG), a teaching hospital.

\section{Data Source}

In the Netherlands, the nationwide population based Netherlands Cancer Registry (NCR) registers all newly diagnosed malignancies. Independently trained data managers from the NCR collect data from original patient files, after receiving an automatic report from the Dutch pathology reporting system PALGA. Completeness of the cancer registry is cross-checked by linking with the Dutch National Registry of Hospital Discharge Diagnosis, which is a nearcomplete registry of hospital discharge data for all in-hospital treatments. Information on patient characteristics, tumor characteristics, treatment, hospital of diagnosis, hospital of treatment, and follow-up is recorded. For coding tumor site and morphology the International Classification of Diseases for Oncology (ICD-0) is used. ${ }^{12}$ Cancers are staged according the TNM classification (TNM classification of Malignant Tumors, 6th edition). ${ }^{13}$ The quality of the data is high, and completeness is estimated to be at least $95 \% .{ }^{14}$ Vital status of all patients was obtained actively on a regular basis through linkage of the cancer registry data with the integrated database of the municipal registry.

The Leiden cancer registry (part of the NCR), collects data of all patients who are diagnosed for a new malignancy in 1 of the affiliated hospitals in the CCCW region. All hospitals gave formal consent to participate.

In addition, after centralization, operating surgeons register all patients who undergo pancreatic surgery (both for malignant and benign diagnoses) in an electronically shared database to monitor the results. Completeness of the data was further cross-checked with linking of the shared database to the cancer registry.

\section{Patient Groups}

Patients with pancreatic surgery for cancer in the region of the CCCW from January 1, 1996 to December 31, 2008 were identified from the NCR, which covered surgically treated malignancies of pancreas (C25), duodenum (C17.0), ampulla of Vater (C24.1), and the hepatic bile duct (C24.0). Patient demographics, pathological notes, TNM staging, and data on surgical and (neo-) adjuvant treatments were collected.

Additional data on comorbidities, detailed postoperative complications, length of stay, and margin status of all patients who underwent pancreatic surgery between 2006 and 2008 for both malignant and benign diagnoses were collected from the shared database.

\section{Outcomes}

Outcomes of pancreatic resections in 3 time periods were compared: 1996-2000, 2001-2005, and 2006-2008. In the first period from 1996 till 2000, no quality control for pancreatic surgery was performed in the region. In 2001, quality standards were implemented and from 2006 pancreatic surgery was centralized in 2 hospitals. Outcome was assessed using 30-day mortality, 90-day survival, 1year survival, and 2-year survival and the number of evaluated lymph nodes. Survival was calculated as the difference between date of surgery, or-if not availablethe date of confirmed diagnosis (which is usually the same as the date of surgery), and, either the date of death, or the date of last patient follow-up. Follow-up of patients was completed until January 1, 2010.

For the period 2006-2008, postoperative complications, length of stay, length of ICU admission, and margin status were also analyzed. 


\section{Statistical Methods}

Descriptive statistics were calculated for all variables. Differences in patient, tumor, and treatment characteristics between the 3 time periods as well as outcome measurements were assessed using the Kruskal-Wallis test (for continuous variables) and chi-square test (for categorical variables).

Observed survival rates were estimated with the Kaplan-Meier method. Differences in survival between the 3 time periods were assessed with the log-rank test. The multivariate Cox proportional hazard model was used to identify factors associated with improved survival after surgery. Period of diagnosis, age, tumor location, histology, stage, and adjuvant chemotherapy and radiotherapy were entered in the multivariate model as prognostic factors. All analyses were conducted with SPSS version 15 (SPSSinc, Chicago, IL).

\section{RESULTS}

\section{Centralization and Referral Pattern}

From 1996 until 2005 pancreatic surgery was performed in all CCCW-affiliated hospitals. The mean annual hospital volume of oncologic pancreatic resections was 1.7 in 1996-2000 and 2.0 in 2001-2005. Since January 1, 2006, all pancreatic surgery was centralized in 2 hospitals. The mean annual hospital volume increased to 23 .

After centralization, the percentage of patients receiving surgical treatment for pancreatic cancer, increased from $14.3 \%$ to $18.4 \%(P=.08)$. The proportion of patients who are living in the CCCW region and had surgery within the region increased from $55 \%$ to $69 \%(P=.085)$.

\section{Characteristics and Crude Outcomes}

Table 1 shows the characteristics of 249 patients who underwent pancreatic surgery for a malignancy from 1996 to 2008 in the CCCW region, stratified by the period of diagnosis. There were no significant differences in patient age, tumor stage, and histology. In the latter period, more patients had a tumor located in the pancreas and chemotherapy use increased from $2.4 \%$ in $1996-2000$, to $23.6 \%$ in 2006-2008.

Table 2 shows the crude outcomes. The 30-day mortality fell from $8 \%$ in the first period to $0 \%$ and $2 \%$ in the latter periods. Testing of statistical significance was not feasible because of low numbers. Of all patients with a malignant tumor, the observed 90-day survival improved from $88 \%$ to $96 \%(P=.03)$, and the 2-year survival from $39 \%$ to $55 \%(P=.09)$. The 2-year survival first dropped from $38 \%$ to $28 \%$ in the first two time periods and then improved to $49 \%$ in the latest period $(P=.04)$.

The median number of evaluated lymph nodes increased significantly from median 2 to median 7 lymph nodes examined.

There was no significant change in observed overall survival $(P=.106$, Fig. 1$)$.

\section{Univariate and Multivariate Analysis of Survival}

In univariate analysis, risk of death was associated with higher age, a tumor located in the pancreas, stage III and IV, adenocarcinoma of the pancreas, and diagnosis in the early periods (Table 3 ).

After adjustment for age, tumor location, histology, stage, and adjuvant therapy, a significant association between the latest period of diagnosis and a lower risk of death was seen (hazard ratio [HR] 0.50; 95\% confidence interval [95\% CI] 0.34-0.73).

Figure 2 shows that after risk adjustment patients diagnosed in the latest period had a significantly better survival compared with patients diagnosed before centralization.

\section{Additional Characteristics and Outcomes 2006-2009}

In the period 2006-2009, in total 213 patients underwent pancreatic surgery in the 2 high-volume hospitals. Almost $25 \%$ of all pancreatic surgery was done for benign diagnosis (53 of 213). Most patients had comorbidity (63\%) and were classified as ASA II $(62 \%)$ or higher (15\%). The Whipple and the PPPD procedure were the most performed procedures $(49 \%)$.

The postoperative mortality was 3.3\% (7 of 213) and $38 \%$ (82 of 213) had postoperative complications. Reintervention was carried out in (18 of 213) $8.6 \%$ of all patients. The median length of stay was 10 days, and the median stay at the ICU was 1 day. The median interval between first contact and surgery was 22 days. Of all patients who had pancreatic surgery for a malignant diagnosis, 115 of 160 (72\%) had tumor-free margins (R0), 29 of 160 (18\%) had microscopic margin involvement (R1), and 1 patient had macroscopic margin involvement (R2). From 15 of $160(10 \%)$ the margin status was unknown.

\section{DISCUSSION}

The present study shows that after centralization of pancreatic surgery, the survival of patients with pancreatic malignancies actually improved. After adjusting for differences in age, tumor stage, location, histology, and adjuvant treatment, a strong association between surgery after centralization and improved survival was shown (HR 
TABLE 1 Characteristics of 249 patients with pancreatic surgery for a malignancy in the western part of the Netherlands between 1996 and 2008 a Other histology includes (neuro)endocrine tumors, carcinoid tumors, and unspecified histology

\begin{tabular}{|c|c|c|c|c|}
\hline & 1996-2000 N (\%) & 2001-2005 N (\%) & $2006-2008 N(\%)$ & $P$ value \\
\hline Total No. of patients & 85 & 89 & 110 & \\
\hline \multicolumn{5}{|l|}{ Gender } \\
\hline Male & $40(47.1)$ & $48(53.9)$ & $52(47.3)$ & \multirow[t]{2}{*}{.572} \\
\hline Female & $45(52.9)$ & $41(46.1)$ & $58(52.7)$ & \\
\hline \multicolumn{5}{|l|}{ Age } \\
\hline$<50$ years & $13(15.3)$ & $16(18.0)$ & $9(8.2)$ & \multirow[t]{3}{*}{.218} \\
\hline $50-74$ years & $60(70.6)$ & $64(71.9)$ & $82(74.5)$ & \\
\hline$\geq 75$ years & $12(14.1)$ & $9(10.1)$ & $19(17.3)$ & \\
\hline \multicolumn{5}{|l|}{ Tumor location } \\
\hline Pancreas & $45(52.9)$ & $60(67.4)$ & $78(70.9)$ & \multirow[t]{3}{*}{.046} \\
\hline Extrahepatic bile duct & $29(34.1)$ & $16(18.0)$ & $22(20.0)$ & \\
\hline Duodenum & $11(12.9)$ & 13 (14.6) & $10(9.1)$ & \\
\hline \multicolumn{5}{|l|}{ Histology } \\
\hline Adenocarcinoma & $72(84.7)$ & $71(79.8)$ & $98(89.1)$ & \multirow[t]{2}{*}{.190} \\
\hline Other $^{\mathrm{a}}$ & $13(15.3)$ & $18(20.2)$ & $12(10.9)$ & \\
\hline \multicolumn{5}{|l|}{ Stage (pTNM) } \\
\hline I-II & $41(48.2)$ & $38(42.7)$ & $40(36.4)$ & \multirow[t]{3}{*}{.073} \\
\hline III-IV & $33(38.8)$ & $31(34.8)$ & $56(50.9)$ & \\
\hline Other & $11(12.9)$ & $20(22.5)$ & $14(12.7)$ & \\
\hline \multicolumn{5}{|l|}{ Chemotherapy } \\
\hline Yes & $2(2.4)$ & $5(5.6)$ & $26(23.6)$ & \multirow[t]{2}{*}{.000} \\
\hline No & 83 (97.6) & $84(94.4)$ & $84(76.4)$ & \\
\hline \multicolumn{5}{|l|}{ Radiotherapy } \\
\hline Yes & $5(5.9)$ & $3(3.4)$ & 0 & \\
\hline No & $80(94.1)$ & 86 (96.6) & $110(100)$ & \\
\hline
\end{tabular}

0.50; 95\% CI 0.34-0.73). In addition, after centralization a higher proportion of patients with pancreatic cancer received surgery.

To date there are 9 studies, reporting the association of concentration of pancreatic care and clinical outcomes (Table 4). ${ }^{15-23}$ Most did not evaluate centralization as an intervention, but described the concentration of care over time. All studies were based on large administrative databases. In-hospital mortality was the outcome parameter in all studies, and only 4 were risk adjusted. None provided information on survival.

Most previous studies showed a beneficial effect of centralization on in-hospital mortality with mortality reductions varying from $12 \%$ to $0.5 \%$. Rosemurgy et al. observed an increased mortality, despite fewer surgeons carried out more pancreatic resections. ${ }^{21}$ This was attributed to the fact that most pancreatic surgery was still done by low-volume surgeons and the mortality rate for surgeons in the lowest volume category increased significantly.

This study shows that centralization in the CCCW region was successful. The centralization was based on regional agreement; thus, the regional availability of surgical care was ensured. A frequently mentioned argument against centralization is the concern that the travel burden is too demanding for patients and their family. ${ }^{24}$ Our results show an increase of patients operated on within their own region. However, travel distances between the nine affiliated hospitals did not exceed $45 \mathrm{~km}$, so the benefit is limited.

The increased burden of pancreatic surgery in the 2 centers did not result in increased waiting times.

The percentage of patients who received surgical treatment for pancreatic cancer increased from $14 \%$ to $18 \%$. Because surgical treatment remains the only potential for curing pancreatic cancer, this can potentially benefit the survival of more patients.

The additional outcomes from the period 2006-2009 of all pancreatic surgery were comparable to reported outcomes of other high-volume centers. The number of evaluated lymph nodes increased significantly (from median 2 to median 7 examined lymph nodes). ${ }^{25}$ The complication rate and the rate of involved margins were acceptable and comparable to previously described rates. ${ }^{26,27}$ The median length of stay of 10 days, is shorter than previously reported. ${ }^{28}$

The present study has several strengths. The NCR provides clinical, population-based data, which are reliable and complete. In addition, a multivariate analysis was 

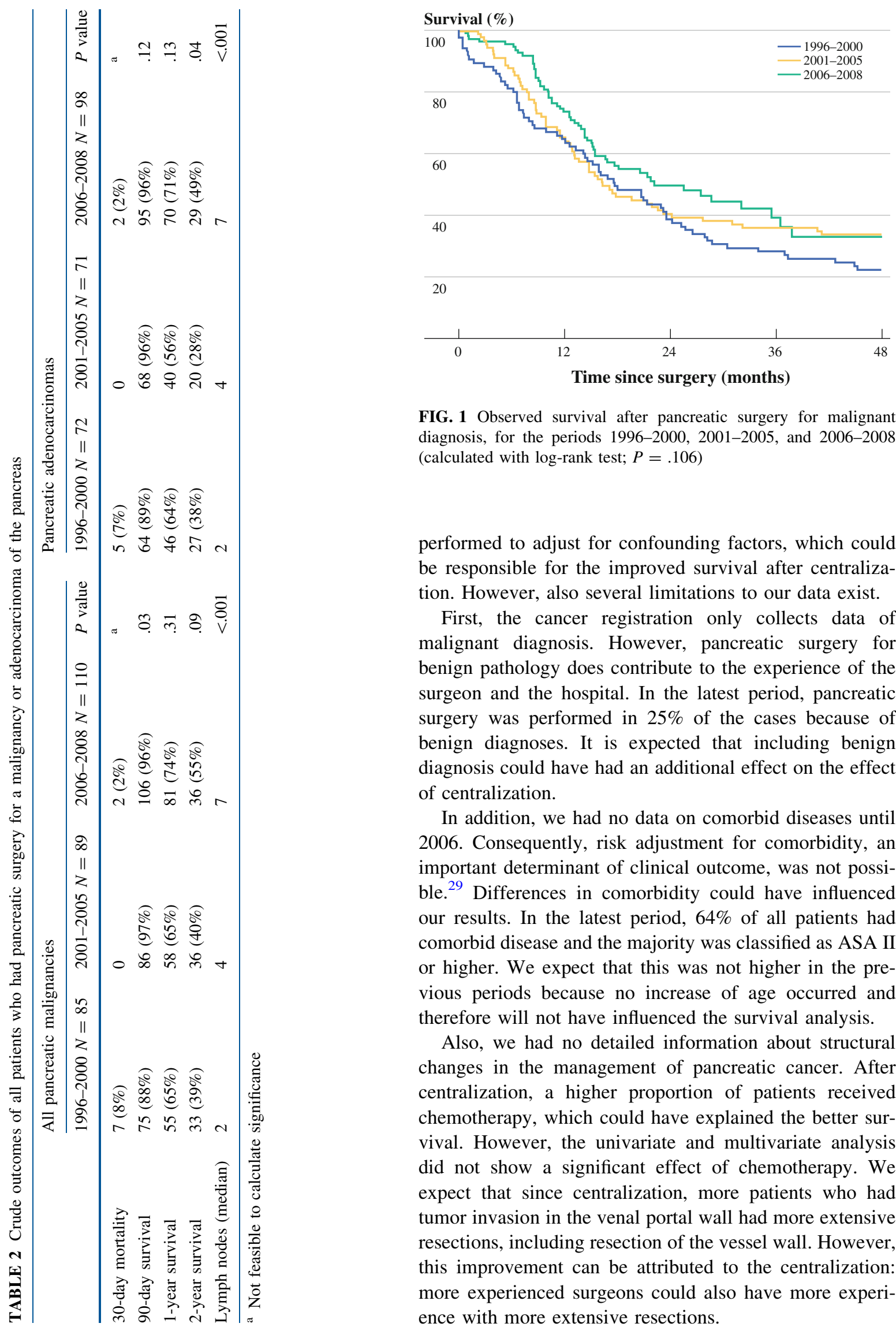

FIG. 1 Observed survival after pancreatic surgery for malignant diagnosis, for the periods 1996-2000, 2001-2005, and 2006-2008 (calculated with log-rank test; $P=.106$ )

performed to adjust for confounding factors, which could be responsible for the improved survival after centralization. However, also several limitations to our data exist.

First, the cancer registration only collects data of malignant diagnosis. However, pancreatic surgery for benign pathology does contribute to the experience of the surgeon and the hospital. In the latest period, pancreatic surgery was performed in $25 \%$ of the cases because of benign diagnoses. It is expected that including benign diagnosis could have had an additional effect on the effect of centralization.

In addition, we had no data on comorbid diseases until 2006. Consequently, risk adjustment for comorbidity, an important determinant of clinical outcome, was not possible. ${ }^{29}$ Differences in comorbidity could have influenced our results. In the latest period, $64 \%$ of all patients had comorbid disease and the majority was classified as ASA II or higher. We expect that this was not higher in the previous periods because no increase of age occurred and therefore will not have influenced the survival analysis.

Also, we had no detailed information about structural changes in the management of pancreatic cancer. After centralization, a higher proportion of patients received chemotherapy, which could have explained the better survival. However, the univariate and multivariate analysis did not show a significant effect of chemotherapy. We expect that since centralization, more patients who had tumor invasion in the venal portal wall had more extensive resections, including resection of the vessel wall. However, this improvement can be attributed to the centralization: more experienced surgeons could also have more experience with more extensive resections. 
TABLE 3 Univariate and multivariate Cox regression analysis of overall survival in $n=274$ patients with pancreatic surgery following diagnosis of cancer in pancreas, ampulla of Vater, extrahepatic bile duct, or duodenum. The risk of dying is presented as hazard ratio (HR) with the $95 \%$ confidence interval $(95 \% \mathrm{CI})$

\begin{tabular}{|c|c|c|c|c|c|c|}
\hline \multirow[t]{2}{*}{ Characteristics } & \multicolumn{3}{|c|}{ Univariate analysis } & \multicolumn{3}{|c|}{ Multivariate analysis } \\
\hline & HR & $95 \% \mathrm{CI}$ & $P$ value & $\mathrm{HR}$ & $95 \% \mathrm{CI}$ & $P$ value \\
\hline Period of diagnosis & & & .11 & & & .001 \\
\hline $1996-2000$ & 1 & - & & 1 & - & \\
\hline 2001-2005 & 0.79 & $0.56-1.11$ & & 0.94 & $0.67-1.33$ & \\
\hline 2006-2007 & 0.69 & $0.49-0.98$ & & 0.50 & $0.34-0.73$ & \\
\hline Age & & & .008 & & & .17 \\
\hline$<50$ years & 1 & - & & 1 & - & \\
\hline $50-74$ years & 2.13 & $1.32-3.44$ & & 1.49 & $0.90-2.46$ & \\
\hline$\geq 75$ years & 1.99 & $1.11-3.58$ & & 1.76 & $0.96-3.22$ & \\
\hline Gender & & & .84 & & & \\
\hline Male & 1 & - & & & & \\
\hline Female & 1.03 & $0.78-1.36$ & & & & \\
\hline Tumor location & & & $<.0001$ & & & $<.0001$ \\
\hline Pancreas (C25) & 1 & - & & 1 & - & \\
\hline Other $(\mathrm{C} 24, \mathrm{C} 17.1)$ & 0.52 & $0.38-0.71$ & & 0.48 & $0.35-0.67$ & \\
\hline Histology & & & $<.0001$ & & & .001 \\
\hline Adenocarcinoma & 1 & - & & 1 & - & \\
\hline Other & 0.29 & $0.18-0.49$ & & 0.31 & $0.15-0.61$ & \\
\hline Stage (pTNM) & & & $<.0001$ & & & $<.0001$ \\
\hline I-II & 1 & - & & 1 & - & \\
\hline III-IV & 2.26 & $1.65-3.08$ & & 2.46 & $1.78-3.42$ & \\
\hline Unknown/no TNM & 0.60 & $0.37-0.99$ & & 1.38 & $0.73-2.60$ & \\
\hline Chemotherapy & & & .42 & & & .81 \\
\hline No & 1 & - & & 1 & - & \\
\hline Yes & 1.20 & $0.77-1.86$ & & 1.07 & $0.63-1.80$ & \\
\hline Radiotherapy & & & .09 & & & .76 \\
\hline No & 1 & - & & 1 & - & \\
\hline Yes & 1.84 & $0.91-3.73$ & & 1.14 & $0.50-2.59$ & \\
\hline
\end{tabular}

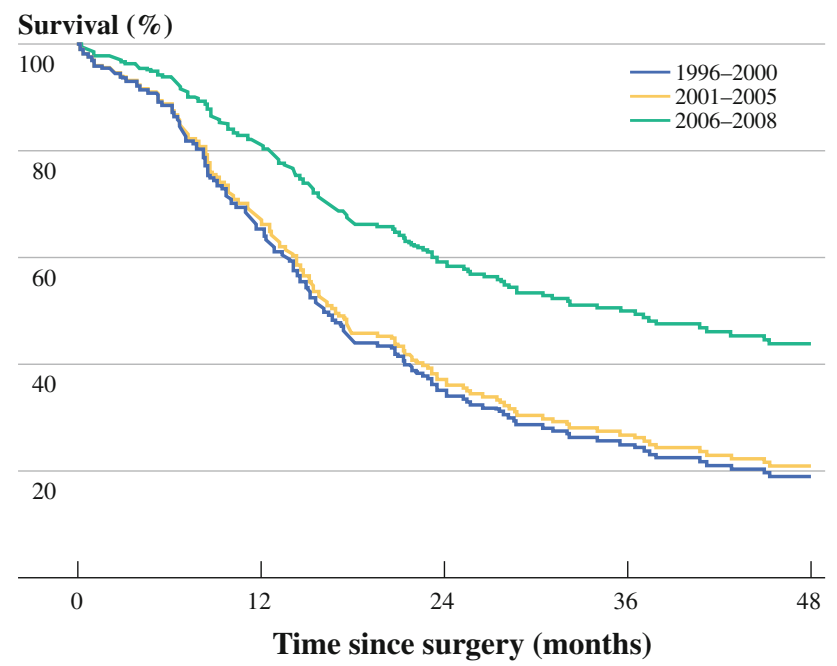

FIG. 2 Survival curves for patients with pancreatic surgery for a malignant diagnosis, after adjustment for age, tumor location, histology, and stage, in the western part of the Netherlands, for the periods 1996-2000, 2001-2005, and 2006-2008
Awareness on quality assurance could have had an intrinsic effect on the practice patterns and the dedication of the surgeons and thus have impact on the quality of care, which is known as the Hawthorne effect. ${ }^{30}$ However, quality standards were already introduced in 2001 and no differences were detected between the first period and the period after the quality initiatives were started.

The improved survival can also be explained by better patient selection for surgery. In the last period the resection rate increased and the majority of the resected patients was classified as ASA II or higher. The primary tumor was more often located in the pancreas and the extrahepatic bile ducts and less in the duodenum. This suggests that more patients were eligible for a resection after centralization.

At last, the improved survival could have been the result of other improvements in the diagnosis, surgical technique, or postoperative care. However, at a national level, no improvement in overall survival of pancreatic cancer during our study period was observed in the Netherlands (source: Netherlands Cancer Registry, available at www.ikcnet.nl). 
TABLE 4 Outcomes reported in previous studies evaluating centralization of pancreatic surgery

\begin{tabular}{|c|c|c|c|c|c|c|c|c|c|c|}
\hline Author & Year & Country & Unit & Period & $\% \mathrm{HVH}$ & $\begin{array}{l}\text { No. hospitals/ } \\
\text { surgeons }^{c}\end{array}$ & $\begin{array}{l}\text { Inhospital } \\
\text { mortality }\end{array}$ & $P$ value & $\mathrm{OR}(\mathrm{CI})$ & $\mathrm{RR}(\mathrm{CI})$ \\
\hline \multirow[t]{2}{*}{ Gordon $^{15}$} & 1998 & USA & Hospital & 1984 & 21 & & 17.2 & & & 1 \\
\hline & & & & $1995^{\mathrm{a}}$ & 59 & & 4.9 & & & $0.92(0.86-0.99)$ \\
\hline \multirow[t]{3}{*}{$\mathrm{Ho}^{16}$} & 2006 & USA & Hospital & 1988-1991 & $2.6^{\mathrm{b}}$ & & 11.4 & & 1 & \\
\hline & & & & 1992-1996 & $3.1^{\mathrm{b}}$ & & 10.0 & & $0.97(0.76-1.23)$ & \\
\hline & & & & $1997-2000$ & $4^{\mathrm{b}}$ & & 8.3 & & $0.91(0.71-1.17)$ & \\
\hline \multirow[t]{2}{*}{ Riall $^{17}$} & 2007 & USA & Hospital & 1999 & 54.5 & & 6.6 & .01 & & \\
\hline & & & & $2004^{\mathrm{a}}$ & 63.3 & & 3.9 & & & \\
\hline \multirow[t]{2}{*}{ McPhee $^{18}$} & 2007 & USA & Hospital & 1988 & 30 & & 7.8 & & $1.49(1.04-2.13)$ & \\
\hline & & & & $2003^{\mathrm{a}}$ & 39 & & 4.6 & & 1 & \\
\hline \multirow[t]{2}{*}{ Langer $^{19}$} & 2007 & Canada & Hospital & 1988-1996 & 18 & 72 & 10.2 & & & \\
\hline & & & & 2002-2004 & 61 & 28 & 4.5 & Not reported & & \\
\hline \multirow[t]{2}{*}{$\mathrm{Pal}^{20}$} & 2008 & UK & Hospital & 1999-2002 & & 101 & 6.2 & & & \\
\hline & & & & 2002-2005 & & 73 & 5.7 & Not reported & & \\
\hline \multirow[t]{2}{*}{ Rosemurgy $^{21}$} & 2008 & USA & Surgeon & 1995-1997 & & 266 & 5.1 & & & \\
\hline & & & & $2003-2005$ & & 282 & 5.9 & .45 & & \\
\hline \multirow[t]{2}{*}{ Stitzenberg $^{22}$} & 2009 & USA & Hospital & 1996 & 35 & & 7.3 & & & \\
\hline & & & & $2006^{\mathrm{a}}$ & 70 & & 3.8 & .001 & & \\
\hline \multirow[t]{3}{*}{ Gasper $^{23}$} & 2009 & USA & Hospitals & 1990-1994 & 28 & & 9.9 & & & \\
\hline & & & & 1995-1999 & 37 & & 7.1 & & & \\
\hline & & & & 2000-2004 & 58 & & 6.0 & Not significant & & \\
\hline
\end{tabular}

${ }^{a}$ Not two separate periods compared but a gradual trend over time between the 2 noted years

b Mean annual hospital volume

${ }^{c}$ No. of hospitals or surgeons performing pancreatic surgery

Although this includes both resected and unresected patients, it can be expected that general improvements in the management of pancreatic cancer would have led to an improved survival at a national level. Nevertheless, progress in techniques could have interfered with our findings.

It is suggested that the beneficial effect of centralization can be explained by better facilities in high-volume centers and more experience of the surgical team, leading to fewer complications, and better treatment adjusted to the patient. ${ }^{31}$ These facilities include specialized diagnostic procedures, anesthetic and postoperative care, radiologic and endoscopic interventions, early recognition and treatment of complications, multidisciplinary teams, knowledge of nutrition, and so forth. It is challenging to identify essential structural characteristics for good quality. ${ }^{32}$ Bilimoria showed differences in the utilization of multimodality therapy between low- and high-volume providers. ${ }^{33}$ Patients with localized pancreatic cancer were more likely to receive pancreatectomy and adjuvant chemoradiation at academic and high-volume centers. This suggests that more frequent use of surgery and chemoradiation may be one of the underlying reasons of improved outcomes in high-volume centers. Our data show an increased utilization of surgery and adjuvant chemotherapy after centralization as well. Nevertheless, after adjusting for adjuvant chemotherapy, survival was still higher after centralization.

\section{Volume Standards}

The evidence for better outcome of complex, low-volume surgical procedures in high-volume centers and the large disparities in quality of care between high- and lowvolume centers have fueled the discussion about centralization. Volume is considered a proxy for high quality of care, and volume standards are recommended to improve patient outcomes. However, a minimum volume standard cannot be identified.

In the region of the CCCW in the Netherlands, centralization was based on mutual agreement to assign each complex, low-volume procedure to a different affiliated hospital. The pancreatic procedures were centralized in 2 hospitals with proven high quality of care and the required facilities to perform pancreatic surgery. In this way, the availability of good care in the region was ensured. This can be an example for future centralization initiatives.

However, bottom-up centralization initiatives are lacking. Despite the plea for centralization, the referral patterns did not change in the Netherlands in the period 1994-2003, 
and only slight changes were seen in the United States in the period 1998-2003. ${ }^{10,18}$ Therefore, a top-down introduction of minimal volume standards might be necessary to improve the outcomes of pancreatic surgery. In the United States, the Leapfrog Group, a coalition of large employers and public and private purchasers of health care, introduced a volume standard for pancreatic resections of 11 procedures per year. ${ }^{34}$ In Europe, minimal volume standards are currently under consideration.

In conclusion, our study shows that centralization has resulted in improved clinical outcomes of patients who underwent pancreatic surgery for a malignancy. Centralization was realized by agreement of the regional network of surgical oncologists and did not require major structural changes in organization, nor did it affect the accessibility of the health care. These results are encouraging and show how centralization initiatives can actually improve quality of care in a straightforward way. Since regional centralization initiatives are lacking, a top-down introduction of minimal volume standards might be an effective approach to improve the quality of care.

ACKNOWLEDGMENT The authors would like to acknowledge the professional network of surgical oncologists and the Comprehensive Cancer Centre West for their advice, and the registrars of the Leiden Cancer Registry for the collection of the data.

OPEN ACCESS This article is distributed under the terms of the Creative Commons Attribution Noncommercial License which permits any noncommercial use, distribution, and reproduction in any medium, provided the original author(s) and source are credited.

\section{REFERENCES}

1. Balzano G, Zerbi A, Capretti G, Rocchetti S, Capitanio V, Di Carlo V. Effect of hospital volume on outcome of pancreaticoduodenectomy in Italy. Br J Surg. 2008;95:357-62.

2. Birkmeyer JD, Finlayson SR, Tosteson AN, Sharp SM, Warshaw AL, Fisher ES. Effect of hospital volume on in-hospital mortality with pancreaticoduodenectomy. Surgery. 1999;125:250-6.

3. Birkmeyer JD, Warshaw AL, Finlayson SR, Grove MR, Tosteson AN. Relationship between hospital volume and late survival after pancreaticoduodenectomy. Surgery. 1999;126:178-83.

4. Fong Y, Gonen M, Rubin D, Radzyner M, Brennan MF. Longterm survival is superior after resection for cancer in high-volume centers. Ann Surg. 2005;242:540-4; discussion 544-7.

5. Simunovic M, To T, Theriault M, Langer B. Relation between hospital surgical volume and outcome for pancreatic resection for neoplasm in a publicly funded health care system. CMAJ. 1999; 160:643-8.

6. Bilimoria KY, Bentrem DJ, Feinglass JM, Stewart AK, Winchester DP, Talamonti MS, et al. Directing surgical quality improvement initiatives: Comparison of perioperative mortality and long-term survival for cancer surgery. J Clin Oncol. 2008;26: 4626-33.

7. Finlayson EV, Goodney PP, Birkmeyer JD. Hospital volume and operative mortality in cancer surgery: a national study. Arch Surg. 2003;138:721-5; discussion 726 .
8. Urbach DR, Bell CM, Austin PC. Differences in operative mortality between high- and low-volume hospitals in Ontario for 5 major surgical procedures: estimating the number of lives potentially saved through regionalization. CMAJ. 2003;168:1409-14.

9. Birkmeyer JD, Finlayson EV, Birkmeyer CM. Volume standards for high-risk surgical procedures: potential benefits of the Leapfrog initiative. Surgery. 2001;130:415-22.

10. van Heek NT, Kuhlmann KF, Scholten RJ, de Castro SM, Busch OR, van Gulik TM, et al. Hospital volume and mortality after pancreatic resection: a systematic review and an evaluation of intervention in the Netherlands. Ann Surg. 2005;242:781-8, discussion 788-90.

11. Wouters MW, Karim-Kos HE, le Cessie S, Wijnhoven BP, Stassen LP, Steup WH, et al. Centralization of esophageal cancer surgery: does it improve clinical outcome? Ann Surg Oncol. 2009;16:1789-98.

12. WHO. International classification of diseases for oncology. 3rd ed. Geneva: WHO; 2000.

13. UICC. TNM classification of malignant tumours. 6th ed. New York: Wiley-Liss; 2002.

14. Schouten LJ, Hoppener P, van den Brandt PA, Knottnerus JA, Jager JJ. Completeness of cancer registration in Limburg, The Netherlands. Int J Epidemiol. 1993;22:369-76.

15. Gordon TA, Bowman HM, Tielsch JM, Bass EB, Burleyson GP, Cameron JL. Statewide regionalization of pancreaticoduodenectomy and its effect on in-hospital mortality. Ann Surg. 1998;228: $71-8$.

16. Ho V, Heslin MJ, Yun H, Howard L. Trends in hospital and surgeon volume and operative mortality for cancer surgery. Ann Surg Oncol. 2006;13:851-8.

17. Riall TS, Eschbach KA, Townsend CM, Jr., Nealon WH, Freeman JL, Goodwin JS. Trends and disparities in regionalization of pancreatic resection. J Gastrointest Surg. 2007;11:1242-51 discussion 1251-2.

18. McPhee JT, Hill JS, Whalen GF, Zayaruzny M, Litwin DE, Sullivan ME, et al. Perioperative mortality for pancreatectomy: a national perspective. Ann Surg. 2007;246:246-53.

19. Langer B. Role of volume outcome data in assuring quality in HPB surgery. HPB (Oxford). 2007;9:330-34.

20. Pal N, Axisa B, Yusof S, Newcombe RG, Wemyss-Holden S, Rhodes M, et al. Volume and outcome for major upper GI surgery in England. J Gastrointest Surg. 2008;12:353-7.

21. Rosemurgy A, Cowgill S, Coe B, Thomas A, Al-Saadi S, Goldin $\mathrm{S}$, et al. Frequency with which surgeons undertake pancreaticoduodenectomy continues to determine length of stay, hospital charges, and in-hospital mortality. J Gastrointest Surg. 2008;12: 442-9.

22. Stitzenberg KB, Sigurdson ER, Egleston BL, Starkey RB, Meropol NJ. Centralization of cancer surgery: implications for patient access to optimal care. J Clin Oncol. 2009;27:4671-8.

23. Gasper WJ, Glidden DV, Jin C, Way LW, Patti MG. Has recognition of the relationship between mortality rates and hospital volume for major cancer surgery in California made a difference?: A follow-up analysis of another decade. Ann Surg. 2009;250:472-83.

24. Birkmeyer JD, Siewers AE, Marth NJ, Goodman DC. Regionalization of high-risk surgery and implications for patient travel times. JAMA. 2003;290:2703-8.

25. Bilimoria KY, Talamonti MS, Wayne JD, Tomlinson JS, Stewart AK, Winchester DP, et al. Effect of hospital type and volume on lymph node evaluation for gastric and pancreatic cancer. Arch Surg. 2008;143:671-8; discussion 678.

26. Bilimoria KY, Talamonti MS, Sener SF, Bilimoria MM, Stewart AK, Winchester DP, et al. Effect of hospital volume on margin status after pancreaticoduodenectomy for cancer. J Am Coll Surg. 2008;207:510-9. 
27. Makowiec F, Post S, Saeger HD, Senninger N, Becker H, Betzler $\mathrm{M}$, et al. Current practice patterns in pancreatic surgery: results of a multi-institutional analysis of seven large surgical departments in Germany with 1454 pancreatic head resections, 1999 to 2004 (German Advanced Surgical Treatment study group). J Gastrointest Surg. 2005;9:1080-6; discussion 1086-7.

28. Dimick JB, Pronovost PJ, Cowan JA, Jr., Lipsett PA, Stanley JC, Upchurch GR, Jr. Variation in postoperative complication rates after high-risk surgery in the United States. Surgery. 2003;134: 534-40; discussion 540-1.

29. Wouters MW, Wijnhoven BP, Karim-Kos HE, Blaauwgeers HG, Stassen LP, Steup WH, et al. High-volume versus low-volume for esophageal resections for cancer: the essential role of casemix adjustments based on clinical data. Ann Surg Oncol. 2008; 15:80-7.
30. Khuri SF, Daley J, Henderson WG. The comparative assessment and improvement of quality of surgical care in the Department of Veterans Affairs. Arch Surg. 2002;137:20-7.

31. Joseph B, Morton JM, Hernandez-Boussard T, Rubinfeld I, Faraj $\mathrm{C}$, Velanovich V. Relationship between hospital volume, system clinical resources, and mortality in pancreatic resection. $J \mathrm{Am}$ Coll Surg. 2009;208:520-7.

32. Birkmeyer JD, Sun Y, Goldfaden A, Birkmeyer NJ, Stukel TA. Volume and process of care in high-risk cancer surgery. Cancer. 2006;106:2476-81.

33. Bilimoria KY, Bentrem DJ, Ko CY, Tomlinson JS, Stewart AK, Winchester DP, et al. Multimodality therapy for pancreatic cancer in the U.S.: utilization, outcomes, and the effect of hospital volume. Cancer. 2007;110:1227-34.

34. Evidence Based Hospital Referral Factsheet 3.0. Washington DC: Leapfrog Group; 2008. 